\title{
Federal Aviation Administration (FAA) airworthiness certification for ceramic matrix composite components in civil aircraft systems
}

\author{
Stephen T. Gonczy \\ Gateway Materials Technology, 221 S. Emerson, Mt. Prospect, IL 60056, USA
}

\begin{abstract}
Ceramic matrix composites (CMCs) are being designed and developed for engine and exhaust components in commercial aviation, because they offer higher temperature capabilities, weight savings, and improved durability compared to metals. The United States Federal Aviation Administration (FAA) issues and enforces regulations and minimum standards covering the safe manufacture, operation, and maintenance of civil aircraft. As new materials, these ceramic composite components will have to meet the certification regulations of the FAA for "airworthiness". The FAA certification process is defined in the Federal Aviation Regulations (Title 14 of the Code of Federal Regulations), FAA policy statements, orders, advisory circulars, technical standard orders, and FAA airworthiness directives. These regulations and documents provide the fundamental requirements and guidelines for design, testing, manufacture, quality assurance, registration, operation, inspection, maintenance, and repair of aircraft systems and parts.

For metallic parts in aircraft, the FAA certification and compliance process is wellestablished for type and airworthiness certification, using ASTM and SAE standards, the MMPDS data handbook, and FAA advisory circulars. In a similar manner for polymer matrix composites (PMC), the PMC industry and the FAA have jointly developed and are refining parallel guidelines for polymer matrix composites (PMCs), using guidance in FAA circulars and the CMH-17 PMC handbook. These documents discuss design methods and codes, material testing, property data development, life/durability assessment, production processes, QA procedures, inspection methods, operational limits, and repairs for PMCs. For ceramic composites, the FAA and the CMC and aerospace community are working together (primarily through the $\mathrm{CMH}-17 \mathrm{CMC}$ handbook) to define and codify key design, production, and regulatory issues that have to be addressed in the certification of CMC components in civil aircraft.
\end{abstract}

\section{Introduction}

Ceramic matrix composites (CMCs) consist of a ceramic matrix reinforced with continuous ceramic fibers, yarns, or woven fabrics. These CMCs exhibit improved strain-to-failure $(0.5 \% \sim 1 \%)$ and improved damage tolerance (from a cumulative damage process), unlike monolithic ceramics that

\footnotetext{
a e-mail: gatewaymt@aol.com; stevegmt@gmail.com
}

This is an Open Access article distributed under the terms of the Creative Commons Attribution License 4.0, which permits unrestricted use, distribution, and reproduction in any medium, provided the original work is properly cited. 


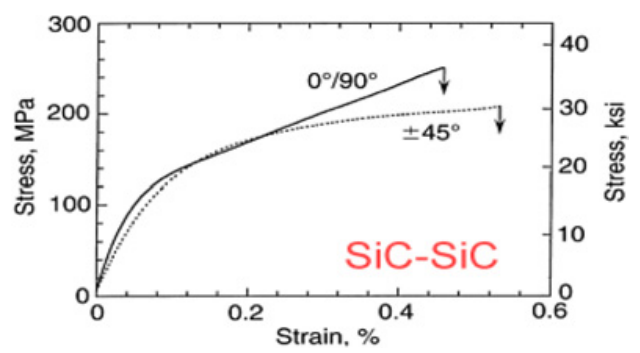

Figure 1. Tensile Stress-Strain of High Density, High Modulus MI SiC Matrix with Nicalon SiC Fiber (w/Fiber Interface Coating).

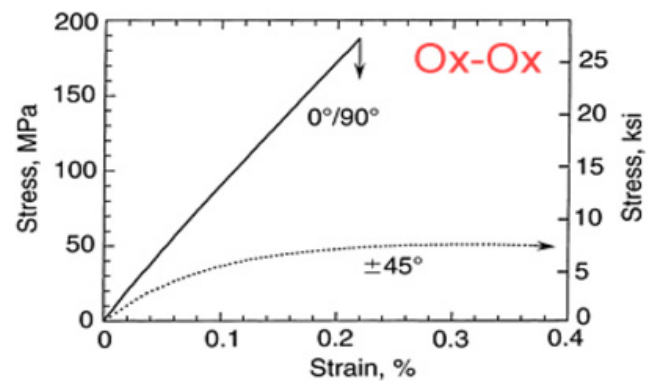

Figure 2. Tensile Stress-Strain Porous, Low Modulus Al-Si-O Matrix on Nextel 720 Alumina Fiber (No Fiber Coating).

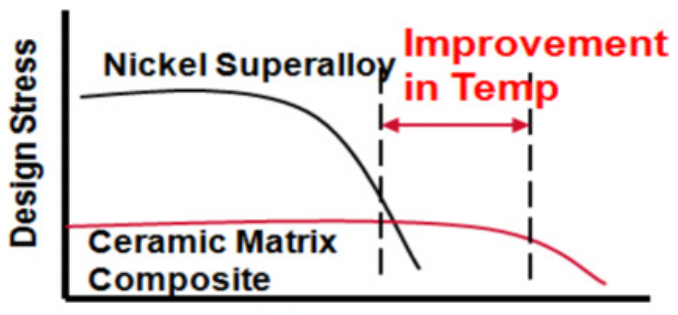

Temperature

Figure 3. Comparative Temperature Capability of Nickel Superalloys and CMCs.

fracture in a brittle catastrophic manner at low strain. (See Figs. 1 and 2.) CMC systems are commonly classified as oxide systems (oxide fibers in alumino-silicate matrices) and non-oxide systems (silicon carbide fibers in silicon-carbide/nitride matrices).

These CMCs are being designed and developed for "hot" engine and exhaust components in military and commercial aviation, because they offer higher temperature capability, weight savings, and improved durability compared to current nickel superalloys (Fig. 3).

Turbine components of direct interest for CMCs are - exhaust components, shrouds/seals, combustors, stators/vanes, and rotors/blades. General Electric and Rolls Royce are currently testing prototype exhaust and shroud components for the GE-CFM LEAP engine, the GE Passport 20 Engine, and the Rolls Royce Trent 1000 engine (Figs. 4 and 5).

As new materials, these ceramic composite components will have to meet the certification requirements of the United States Federal Aviation Administration (FAA) for "airworthiness". The term 


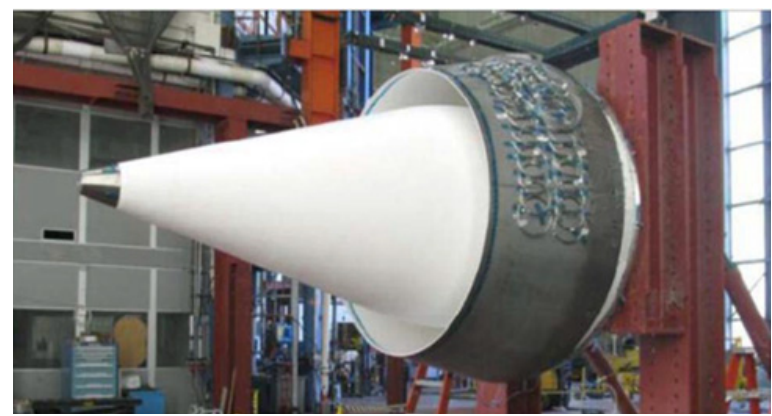

Figure 4. Oxide-Oxide CMC Nozzle and Center Body ( $90^{\prime \prime}$ Long, 40" Ø) FAA CLEEN Program (Boeing, ATK-COIC, AEC, Rolls Royce) Trent 1000 Engine.

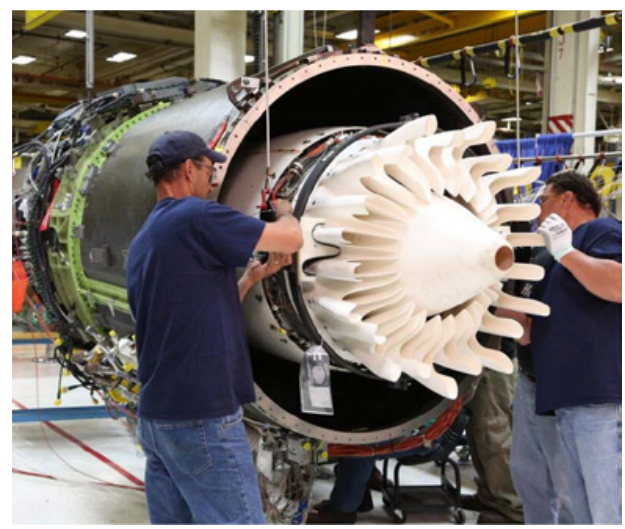

Figure 5. Oxide-Oxide CMC Mixer, Center Body, and Engine Core Cowl on the GE Passport 20 Engine.

"airworthiness" is defined as "that condition of an aircraft, engine, propeller, appliance, or component part where it conforms to its approved type design and is in a condition for safe operation (14 CFR s.3.5)"'.

\section{Federal Aviation Agency responsibilities}

In the United States the Federal Aviation Agency (FAA) has authority to regulate and oversee all aspects of American civil aviation. The mission of the FAA is to provide the safest, most efficient aerospace system in the world. The primary responsibilities of the FAA are:

- Regulating civil aviation to promote safety - the safe manufacture, operation, and maintenance of civil aircraft.

- Developing and operating a system of air traffic control and navigation for both civil and military aircraft.

- Encouraging and developing civil aeronautics, including new aviation technology.

- Researching and developing the National Airspace System and civil aeronautics.

- Developing and carrying out programs to control aircraft noise and other environmental effects of civil aviation.

- Regulating U.S. commercial space transportation. 


\section{Federal Aviation regulations}

The FAA regulations that govern today's aircraft are found in Title 14 of the Code of Federal Regulations (14 CFR). For all aerospace materials engineers and designers the "foundation" regulations in 14 CFR are -

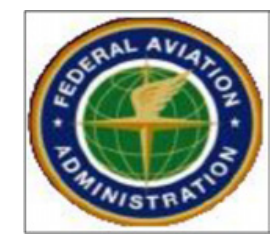

14 CFR Sec. 25.601 - General. - The airplane may not have design features or details that experience has shown to be hazardous or unreliable. The suitability of each questionable design detail and part must be established by tests.

14 CFR Sec. 25.603 - Materials. - The suitability and durability of materials used for parts, the failure of which could adversely affect safety, must -

(a) Be established on the basis of experience or tests;

(b) Conform to approved specifications (such as industry or military specifications, or Technical Standard Orders) that ensure their having the strength and other properties assumed in the design data; and

(c) Take into account the effects of environmental conditions, such as temperature and humidity, expected in service.

\section{CFR 25.605 - Fabrication methods}

(a) The methods of fabrication used must produce a consistently sound structure. If a fabrication process (such as gluing, spot welding, or heat treating) requires close control to reach this objective, the process must be performed under an approved process specification.

(b) Each new aircraft fabrication method must be substantiated by a test program.

14 CFR Sec. 25.609. - Protection of structure. Each part of the structure must be suitably protected against deterioration or loss of strength in service due to any cause, including -

(1) Weathering;

(2) Corrosion;

(3) Abrasion; and

(4) Have provisions for ventilation and drainage where necessary for protection.

14 CFR Sec. 25.629. - Aeroelastic stability requirements.

(a) General. The aeroelastic stability evaluations required under this section include flutter, divergence, control reversal and any undue loss of stability and control as a result of structural deformation. The aeroelastic evaluation must include whirl modes associated with any propeller or rotating device that contributes significant dynamic forces. Compliance with this section must be shown by analyses, wind tunnel tests, ground vibration tests, flight tests, or other means found necessary by the Administrator.

(b) Each new aircraft fabrication method must be substantiated by a test program.

14 CFR Sec. 26.613. - Material strength properties and design values.

(a) Material strength properties must be based on enough tests of material meeting approved specifications to establish design values on a statistical basis. 
(b) Design values must be chosen to minimize the probability of structural failures due to material variability. Except as provided in paragraph (e) of this section, compliance with this paragraph must be shown by selecting design values which assure material strength with the following probability:

(1) Where applied loads are eventually distributed through a single member within an assembly, the failure of which would result in loss of structural integrity of the component, 99 percent probability with 95 percent confidence.

(2) For redundant structure, in which the failure of individual elements would result in applied loads being safely distributed to other load carrying members, 90 percent probability with 95 percent confidence.

(c) The effects of temperature on allowable stresses used for design in an essential component or structure must be considered where thermal effects are significant under normal operating conditions.

(d) The strength, detail design, and fabrication of the structure must minimize the probability of disastrous fatigue failure, particularly at points of stress concentration.

(e) Greater design values may be used if a "premium selection" of the material is made in which a specimen of each individual item is tested before use to determine that the actual strength properties of that particular item will equal or exceed those used in design.

\section{FAA aircraft certificates and approvals}

FAA aircraft certificates and approvals are issued in six formats -

- Airworthiness Certificate (AC) - approval to operate a specific aircraft.

- Type Certification (TC) - design certification for new aircraft/airframes, engines, and propellers.

- Production Certificate (PC) - approval to manufacture parts, components and systems.

- Supplemental Type Certificate (STC) - certification of a modification of aircraft, engine, or propeller (design, manufacture and install).

- Parts Manufacturer Approval - certify replacement parts (third party).

- Technical Standard Order (TSO) - written specification published by FAA on materials, parts, and appliances.

Note that these certificates are for defined systems, products, components, and parts, not for material systems, alloys, or composite types.

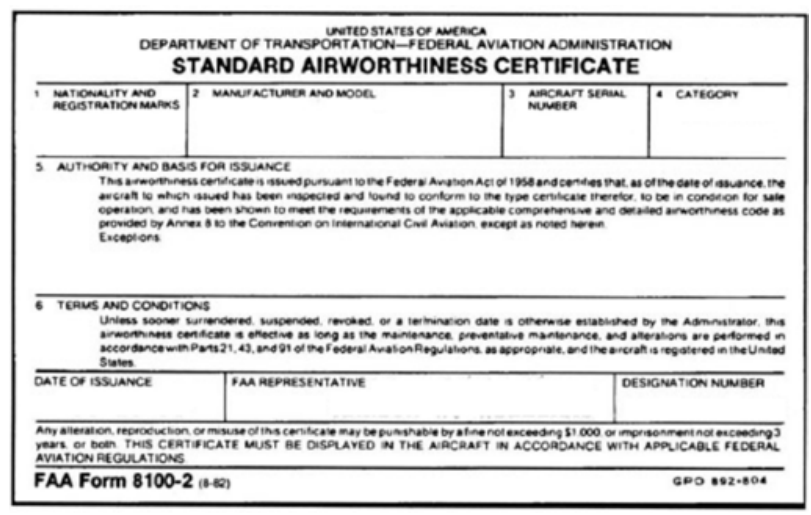




\section{The FAA certification process}

The FAA certification process is defined and detailed through the following FAA documents.

(http://www.faa.gov/regulations_policies/)

- Part 21 of the 14 CFR - Certification Procedures for Products and Parts.

- FAA Policy Statements and Memos - policy directives and direction.

- FAA Orders - procedural rules and regulations.

- FAA Advisory Circulars (AC) - guidance documents for all aspects of design, production, operation, inspection, maintenance, and repair. These circulars are the primary detailed guidance on certification of components made of specific materials.

- FAA Technical Standard Orders (TSO) - minimum performance standard issued by the Administrator for specified materials, parts, processes, and appliances used on civil aircraft.

- FAA Airworthiness Directives - legally enforceable regulations issued by the FAA in accordance with 14 CFR part 39 to correct an unsafe condition in a product.

- FAA Technical Reports.

- FAA and Industry Guide to Product Certification - A guide to the current certification process.

The FAA certification approval process has three stages - design approval (Type and Supplemental Type Certificates, Technical Standard Order, production approval (Production Certificate and Parts Manufacture Approval, Technical Standard Order) and operation and maintenance approval (Regulations, STCs, FAA Orders, and Advisory Circulars, Aircraft Handbooks and Manuals, Airworthiness Directives).

Design approval certifies that a given design meets operational, safety, and durability requirements. The design approval covers: Functional Design Definition, Validation and Documentation, Structural Substantiation (Static, Operational Temps), Manufacturing Process Definition and Documentation, Bonding/Assembly/Integration Design and Validation, Environmental Exposure, Damage Tolerance, Degradation Definition and Assessment, Impact Events, Fatigue and Creep, Fire Protection and Flammability, Lightening Strikes, Crashworthiness, and Inspection and Repair.

Production approval ensures that a defined manufacturing process produces parts that consistently meet design specifications and tolerances; it includes Process Definition and Verification, Critical Manufacturing Steps and Control, Quality Control System With Records, Defect Detection and Disposition.

Operation and Field Maintenance approval covers: Damage Detection, Inspection and Assessment; Repair Criteria and Validated Repair Methods; and Life Prediction and Assessment.

The certification process (for supplemental type certificate) is outlined and described in the "FAA and Industry Guide to Product Certification" (Sep. 2004 - 117 pages). The process has five phases - conceptual design, requirements definition, compliance planning, implementation, and post certification. The certification process is a joint effort between the applicant team and the FAA team, based on communication, teamwork, and accountability from the beginning of the product development effort (requirements and design) through production, fielding, operation, and maintenance/ support.

\section{The FAA certification of metal and polymer matrix composites components}

The FAA certification process for metal parts and products (aluminum, steel, titanium, magnesium, etc.) is well established and detailed. The process uses FAA advisory circulars; industrial design practices; ASTM test standards, AMS and ASTM specifications for composition, processing, properties; certified 
production, assembly, inspection and repair techniques; and the formal MMPDS handbook (Metallic Materials Properties, Development \& Standardization). The MMPDS handbook provides -

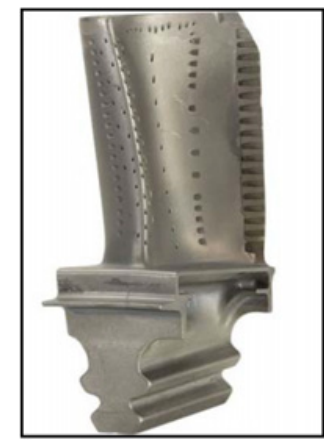

- Design Allowables for Metal Alloys in Aircraft, based on AMS Alloy Specifications.

- Required properties (tension, compression, shear, bearing) by ASTM tests.

- Recommended properties (fatigue, crack growth, fracture toughness, effect of temperature) by ASTM tests.

- Fastener and joint data.

For Polymer matrix composites (PMCs), the guidance and direction for FAA certification is more challenging (than for metals), because of the increased complexity of PMCs (anisotropy, composition complexity, production challenges, different failure and damage modes, different bonding and joining methods, inspection challenges, and repairability issues). The PMC certification process is a dynamic and growing effort based on historical and advancing policy and guidance developed by the designers, producers, users, and the FAA technical staff. The following references show the scope and level of detail that are defined in FAA documents for PMC part certification.

FAA Policy Statements for Composites

- Static Strength Substantiation of Composite Airplane Structure [PS-ACE100-2001-006, Dec. 2006].

- Final Policy for Flammability Testing per 14 CFR Part 23, Sections 23.853, 23.855 and 23.1359 [PS-ACE100-2001-002, Jan. 2002].

- Material Qualification and Equivalency for Polymer Matrix Composite Material Systems [PS-ACE100-2002-006, Sep. 2003].

- Bonded Joints and Structures - Technical Issues and Certification Considerations [PS-ACE1002005-10038, Sep. 2005].

FAA Advisory Circulars for Composites and Materials

AC 20-107B - Composite Aircraft Structure.

AC 21-26 - Quality Control for the Manufacture of Composite Structures.

AC 23-20 - Acceptance Guidance on Material Procurement and Process Specifications for Polymer Matrix Composite Systems.

AC 25.571-1C - Damage Tolerance and Fatigue Evaluation of Structure.

AC 25.613-1 - Material Strength Properties and Material Design Values.

AC 35.37-1A - Guidance Material for Fatigue Limit Tests and Composite Blade Fatigue Substantiation.

AC 500-009 - Composite Aircraft Structure.

AC 21-40a - Guide for Obtaining a Supplemental Type Certificate. 
FAA Technical Reports

"Certification Testing Methodology for Composite Structures, Volumes I and II" [DOT/FAA/CT86/39, Oct. 1986].

"Handbook: Manufacturing Advanced Composite Components for Airframes" [DOT/FAA/AR96/75, Apr. 1997].

"Advanced Certification Methodology for Composite Structures" [DOT/FAA/AR-96/111, Apr. 1997].

"Material Qualification and Equivalency for Polymer Matrix Composite Material Systems" [DOT/FAA/AR-03/19, Sep. 2003].

"Guidelines and Recommended Criteria for the Development of a Material Specification for Carbon Fiber/Epoxy Unidirectional Prepregs" [DOT/FAA/AR-02/109, Mar. 2003].

"Guidelines for the Development of Process Specifications, Instructions, and Controls for the Fabrication of Fiber-Reinforced Polymer Composites" [DOT/FAA/AR-02/110, Mar. 2003].

"Guidelines for Analysis, Testing, and Nondestructive Inspection of Impact-Damaged Composite Sandwich Structures" [DOT/FAA/AR-02/bib121, March 2003].

"Assessment of Industry Practices for Aircraft Bonded Joints and Structures" [DOT/FAA/AR-05/13, July 2005].

AMT Airframe Handbook Volume 2 (FAA-H-8083-31), - Chapter 7 Advanced Composites PMCs.

\section{CMH-17 Handbook Volumes 1, 2, 3, and 6}

Vol. 1 PMC: Guidelines for Characterization of Structural Materials (156 pages).

Vol. 2 PMC: Material Properties (671 pages).

Vol. 3 PMC: Materials Usage, Design and Analysis (852 pages).

Vol. 6 Structural Sandwich Composites (105 pages).

These documents provide guidance on design methods and codes, material testing, property data development, life and durability assessment, production processes, QA procedures, inspection methods, operational limits, and repairs for PMCs.

\section{FAA certification of $\mathrm{CMC}$ components}

Ceramic Matrix Composites (CMCs) have both similarities to and differences with PMCs. CMCs are similar in terms of: composite complexity, anisotropy, fiber architecture; high strength, high stiffness fibers; and production process sensitivity and variability. CMCs are different in the following factors: use at higher temperatures $\left(>500^{\circ} \mathrm{C}\right)$; different ceramic constituents with added levels of complexity (fiber interfaces, porosity, and MI metal); Broader range of constituents (Oxide, non-oxide, silicon carbide, silicon nitride, carbon, etc.) and various assembly/consolidation /densification methods (CVI, MI, PDC, sinter); brittle, low strain matrix with early damage accumulation; different degradation, damage, and failure mechanisms; high temperature $\left(>500^{\circ} \mathrm{C}\right)$ challenges in life prediction and component joining; and ceramic specific challenges in ND Inspection and repairability.

For certification of a given CMC component, the CMC producer and user will have to show the FAA that the part -

- is well-designed for operation, safety, durability, and producibility,

- risks are managed and life limits are determined,

- is tested and analyzed to certify safety and life,

- variability is assessed and managed,

- can be manufactured reliably with certified quality control,

- is inspected for flaws off the production line, 


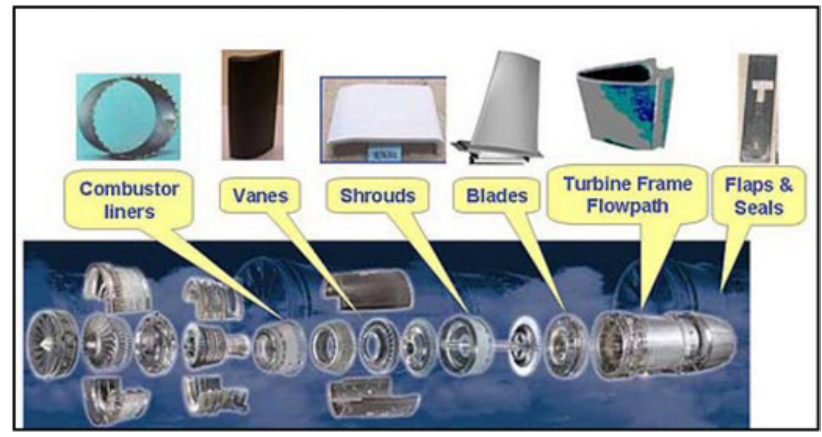

Figure 6. Candidate Components for CMCs in Aircraft Turbine Engines.

- is integrated and installed in the system (joining and assembly),

- can be maintained and inspected in service,

- can be repaired or replaced in service.

Based on the similarities to PMCs, the CMC community can use the PMC certification guidance and tools as a template and baseline for CMC certification; but that PMC policy, guidance, and tools will have to be modified and expanded to address the differences in CMCs.

The near-term challenge for the CMC community is how the OEM's and producers will team with the FAA to define, formalize, and document the details of the certification process for CMCs.

The CMH-17 CMC handbook (Vol. 5) is a major part of this CMC effort, with a focus on design, production, testing and evaluation, data development, and supportability. But the CMH-17 CMC handbook effort is an source for information developed by the CMC community. The CMC producers and users have responsibility to develop, validate and document the many "technical tools" for CMCs:

- Design criteria, approaches, and methods.

- Test standards for mechanical, thermal, and physical properties.

- Analytical methods - stress, thermal, life prediction.

- Degradation, damage, and failure mechanisms and models at different temperatures and environments.

- Property data bases.

- Process control techniques and quality assurance protocols.

- Inspection methods (production line and field).

- Maintenance and repair techniques.

Materials simulation and numerical models will be critical tools for CMC design codes, material assessment, life prediction, and production control.

\section{Summary and conclusions}

Ceramic matrix composites (CMCs) are being developed, designed and will be produced for engine and exhaust components in commercial aviation. Those CMC components will have to be certified by the FAA for commercial use.

The FAA and industry are now working together (primarily through the CMH-17 CMC handbook) to define and codify key design, production, operation, and regulatory issues that have to be addressed in the certification of CMC components in civil aircraft. 
Looking forward, the major challenges in CMC certification are:

1. FAA certification of CMCs has to happen, if we want CMCs on commercial planes.

2. There is so much CMC technology to develop, validate, and document to obtain certification of a given CMC part.

3. The CMC community and the FAA should use the FAA Advisory Circulars for PMCs and the CMH-17 PMC handbook as templates and models for documenting CMC guidance and tools.

4. The CMC community has to work closely with the FAA early in the certification process to keep the FAA fully-informed and current on CMC design, testing, production, operation, inspection, and support technology.

\section{References}

- FAA Web site - http://www.faa.gov/

- Title 14 Code of Federal Regulations

- Chap 12 - Title 14 of the Code of Federal Regulations (14 CFR)

- FAA and Industry Guide to Product Certification (FAA Sep. 2004)

- Aircraft Structure Certification and Compliance (Chap. 3, Vol. 3 (PMC), CMH-17 Handbook)

- Airworthiness: An Introduction to Aircraft Certification By Filippo De Florio (2006)

- FAA AC 21-23b, Airworthiness Certification of Civil Aircraft, Engine, Propellers, and Related Products Imported to the United States

- FAA AC 21-40a, Guide for Obtaining a Supplemental Type Certificate

- "Airworthiness Certification of Aircraft and Related Products" (FAA, July 2012)

- "A Report from the Aircraft Certification Process Review and Reform Aviation Rulemaking Committee to the Federal Aviation Administration Recommendations on the Assessment of the Certification and Approval Process" (FAA. May 2012)

- Aviation Maintenance Technician Handbook - FAA 8083-30. 